Case Report

\title{
The Cytoreductive Effect of Radiotherapy for Small Cell Ovarian Carcinoma of the Pulmonary Type: A Case Report and Review of the Literature
}

\author{
Shuhei Terada $\mathbb{D}$, Takashi Suzuki, Akihiro Hasegawa, \\ Satoru Nakayama, and Hiroshi Adachi \\ Department of Gynecology, Seirei Hamamatsu General Hospital, 2-12-12 Sumiyoshi, Naka-ku, Hamamatsu, Shizuoka 430-8558, Japan \\ Correspondence should be addressed to Shuhei Terada; shuheiterada@gmail.com
}

Received 17 November 2017; Accepted 19 December 2017; Published 16 January 2018

Academic Editor: Maria Grazia Porpora

Copyright (C) 2018 Shuhei Terada et al. This is an open access article distributed under the Creative Commons Attribution License, which permits unrestricted use, distribution, and reproduction in any medium, provided the original work is properly cited.

Small cell ovarian carcinoma of the pulmonary type is a rare and highly aggressive tumor for which a suitable treatment strategy has not been established. A 45-year-old woman presented with abdominal swelling, and primary ovarian carcinoma was suspected. The postoperative pathological diagnosis was small cell ovarian carcinoma of the pulmonary type. She also had complicated grade 1 endometrioid carcinoma of the uterine corpus. Three courses of cisplatin and etoposide therapy were administered as adjuvant chemotherapy. Because the tumor was chemotherapy resistant, she underwent palliative abdominal irradiation at a dose of $26 \mathrm{~Gy}$ in 13 fractions, which induced cytoreduction and provided symptomatic relief. She died 4 months after surgery. Lactate dehydrogenase was a useful tumor marker during treatment. Here, we present an extremely rare case of a patient with small cell ovarian carcinoma of the pulmonary type treated with radiotherapy after surgery and chemotherapy.

\section{Introduction}

Small cell ovarian carcinoma pulmonary type (SCOCPT) is defined as a small cell carcinoma that resembles a neuroendocrine type of pulmonary small cell carcinoma. Most patients with SCOCPT are postmenopausal and present with symptoms such as a pelvic or abdominal mass. SCOCPTs are highly aggressive neoplasms, which usually present at an advanced stage, and the overall prognosis is poor. Only 26 cases of SCOCPT have been reported in the literature, and most patients have typically been treated with surgery followed by chemotherapy. Palliative brain irradiation was administered to control seizures in the previous report [1], but the cytoreductive effect of radiotherapy on the primary lesions is unknown. Here we present a case in which a patient with chemotherapy-resistant SCOCPT underwent abdominal radiotherapy. We describe the outcomes of the radiotherapy and also present evidence on lactate dehydrogenase (LDH) potentially acting as a good tumor marker during the course of treatment.

\section{Case Presentation}

A 45-year-old woman (gravida 1, para 1) presented at our hospital with abdominal swelling. She had undergone laser ablation of cervical intraepithelial neoplasia 3 (CIN3) 12 years previously. She had a family history of paternal prostate cancer. Physical examination showed a large solid tumor in her pelvic region. Abdominal magnetic resonance imaging (MRI) identified a unilateral ovarian mass and small ascites. The tumor, approximately $12 \mathrm{~cm}$ in diameter, revealed a mixed pattern of multicystic and solid parts. Uterine endometrial thickening was also observed, and endometrial biopsy revealed grade 1 endometrioid carcinoma. Computed tomography (CT) revealed no lymph node metastasis or extrapelvic tumors. The laboratory data showed an elevated level of LDH ( $1246 \mathrm{U} / \mathrm{L}$, normal < $210 \mathrm{U} / \mathrm{L})$. Isozyme analysis results were as follows: LD1 15\%, LD2 30\%, LD3 27\%, LD4 $18 \%$, and LD5 10\%. The serum level of cancer antigen 125 (CA125) was $156.7 \mathrm{U} / \mathrm{mL}$ (normal < $35 \mathrm{U} / \mathrm{mL}$ ). The serum calcium level was normal. Double cancer of the ovary and endometrium was suspected, and a staging laparotomy was 


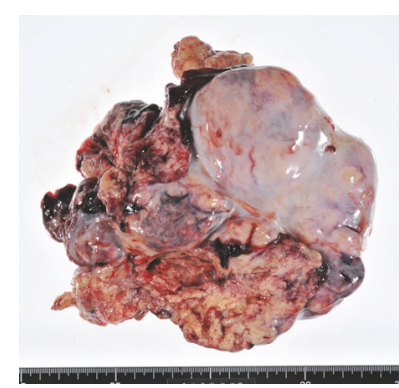

(a)

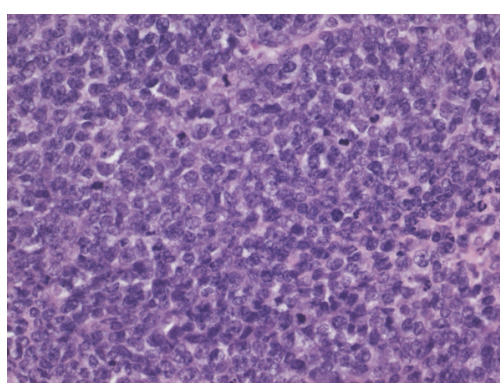

(b)

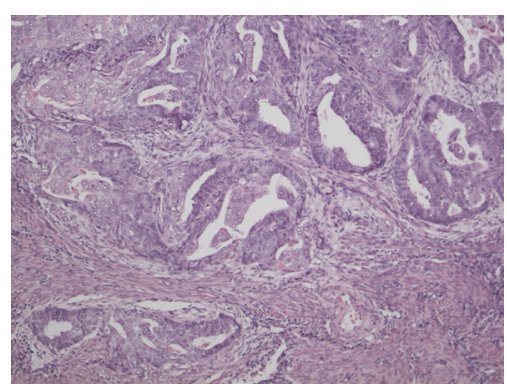

(c)

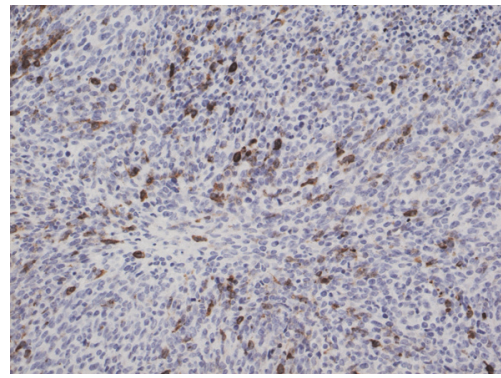

(d)

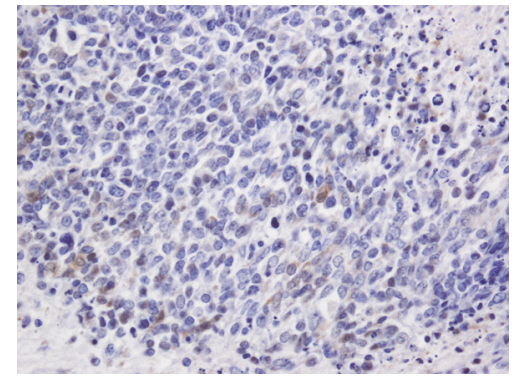

(e)

FIgURE 1: (a) Macroscopic findings: an irregular, white, and solid tumor of the right ovary. ((b)-(d)) Microscopic findings. (b) Tumor cells are round to ovoid with hyperchromatic nuclei, scant cytoplasm, abundant mitosis, and apoptosis with conspicuous necrosis (hematoxylin-eosin stain $(\mathrm{HE}), \times 300)$. (c) Endometrial carcinoma grade 1 in uterine corpus (HE, $\times 30$ ) with less than half myometrial invasion and no vascular invasion. ((d), (e)) Tumor cells are positive for synaptophysin and neuron-specific enolase (immunostaining, $\times 300)$.

scheduled. Eighteen days after first consultation, the patient complained of severe abdominal pain, and ultrasonography revealed that the tumor had enlarged to $16 \mathrm{~cm}$ in diameter, with an accumulation of ascitic fluid and newly diagnosed peritoneal dissemination. The tumor was rapidly progressing, and tumor rupture was also suspected. She underwent an urgent laparotomy, which revealed that a white and solid tumor of the right ovary had spontaneously ruptured in the intra-abdominal cavity (Figure 1(a)). There was massive bloody ascites of approximately $2700 \mathrm{~mL}$ in volume. The tumor was strongly adherent to the bladder and sigmoid colon and was difficult to decorticate. Multiple, but small, peritoneal disseminations were observed in the pelvic cavity. Total abdominal hysterectomy, bilateral salpingooophorectomy, and partial omentectomy were performed, and a $5 \times 4 \mathrm{~cm}$ tumor remained behind the bladder due to the strong adhesion. The pathological diagnosis was SCOCPT (Figure 1(b)) and grade 1 endometrioid carcinoma of the uterine corpus (Figure 1(c)). Immunostaining of the ovarian tumor was positive for epithelial membrane antigen, synaptophysin (Figure 1(d)), neuron-specific enolase (NSE) (Figure 1(e)), p16, and cluster of differentiation (CD) 56 and negative for cytokeratin 20, Wilms Tumor 1, thyroid transcription factor 1, and anti-cytokeratin (CK) antibodies CK18, CK19, and CD99. Thus, we diagnosed primary ovarian cancer stage IIIC (pT3cNxM0) and endometrial cancer stage IA (pTlaNxM0) according to the International Federation of Gynecology and Obstetrics classification system. The serum level of NSE after surgery was $28.1 \mathrm{ng} / \mathrm{mL}$ (normal < $16.3 \mathrm{ng} / \mathrm{mL}$ ).
Twenty days after surgery, a CT scan revealed that the remaining tumor in the pelvic cavity had enlarged to $14.8 \mathrm{~cm}$. At 21 days after surgery, the patient received adjuvant chemotherapy combining cisplatin $\left(60 \mathrm{mg} / \mathrm{m}^{2}\right.$ on day 1$)$ and etoposide $\left(100 \mathrm{mg} / \mathrm{m}^{2}\right.$ on days 1 to 3 ) administered every 3 weeks by intravenous infusion. After each course, CT scanning revealed slight shrinkage of the residual tumor, but it enlarged during the drug holidays. After 3 courses of this regimen, the tumor was observed to have enlarged to $20.3 \mathrm{~cm}$ on CT. The patient's performance status, as measured using the Eastern Cooperative Oncology Group (ECOG) grading scale, was grade 3 , and she complained of abdominal swelling. Therefore, irradiation of the abdominal tumor was initiated. A total dose of $26 \mathrm{~Gy}$ was given in 13 fractions, and the tumor size decreased to $15.3 \mathrm{~cm}$ with improved symptoms (Figure 2). However, several hypointensity lesions suggestive of intratumor gas were observed in the pelvic tumor. The patient gradually felt severely fatigued and refused any treatment. She was transferred to a hospice and died 135 days after the surgery. An autopsy was not performed. During the course of treatment, serum LDH levels repeatedly decreased soon after the chemotherapy but increased during drug holidays (Figure 3).

\section{Discussion}

We identified two important clinical issues. Palliative radiotherapy for SCOCPT can be considered in patients with abdominal swelling, and LDH is a useful tumor marker. 


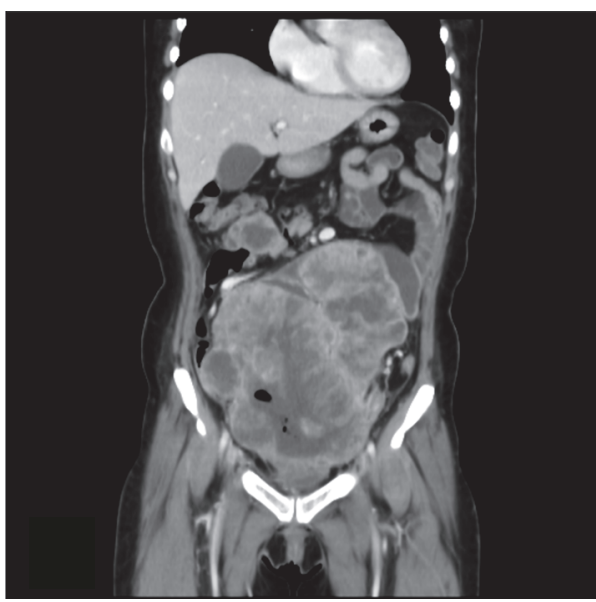

(a)

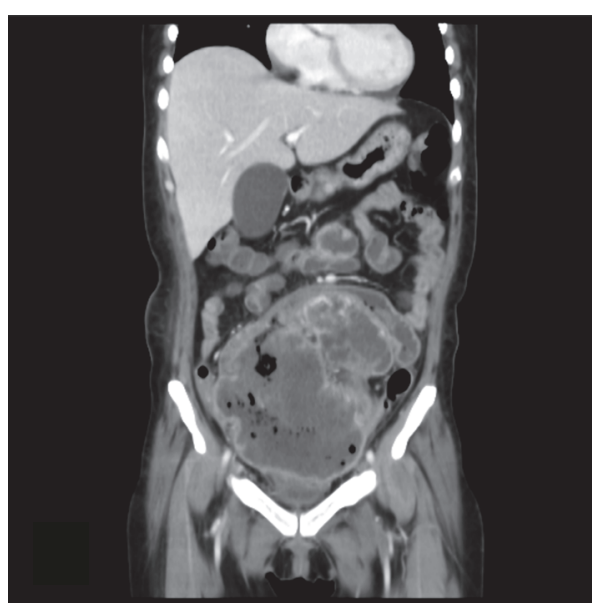

(b)

FIGURE 2: (a) Enhanced abdominal computed tomography (coronal section) reveals the remaining tumor is approximately $20.3 \mathrm{~cm}$ in diameter before irradiation. (b) After radiation therapy, the tumor size decreased to $15.3 \mathrm{~cm}$.

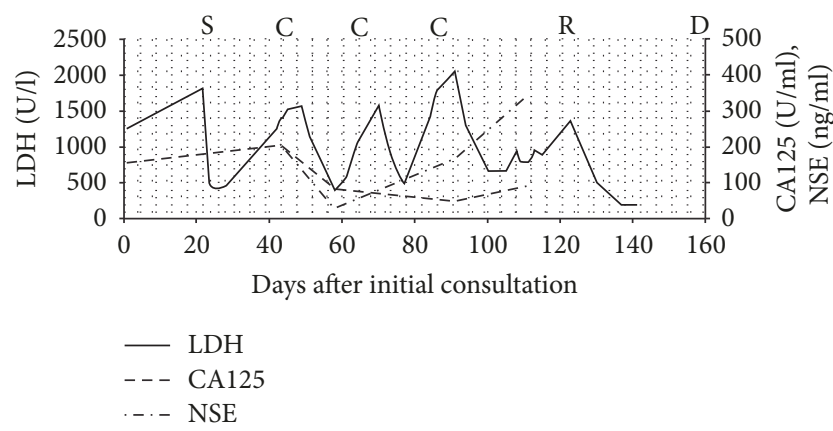

Figure 3: The graph shows the time course of the levels of serum lactate dehydrogenase (LDH), cancer antigen 125 (CA125), and neuron-specific enolase (NSE). The patient underwent surgery (S) on day 21; chemotherapy (C) on days 43,65 , and 86 ; and abdominal irradiation (R) from day 120 to day 140 . She died on day 157 (D). The solid line shows levels of $\mathrm{LDH}$, the dashed-line shows levels of CA125, and the dashed-dotted line shows levels of NSE.

First, with regard to palliative radiotherapy as a cytoreductive effect for SCOCPT, a total of 26 cases of SCOCPT have been reported in the literature, and 18 of these were treated with chemotherapy postoperatively (Table 1) [1-15]. To our knowledge, this is the first report of SCOCPT treated with radiotherapy except for brain irradiation to control seizures with brain metastasis. Palliative radiotherapy at a dose of $26 \mathrm{~Gy}$ for the residual abdominal tumor contributed to tumor shrinkage by approximately $25 \%$. Intratumor gas was observed, but it was not ascertained that the fistula between the tumor and the intestines was attributable to radiotherapy. It is not clear if radiotherapy improved the prognosis. However, we believe that radiotherapy was at least effective for improving the symptoms associated with tumor enlargement.

There are many reports regarding the effectiveness of radiotherapy in small cell carcinoma in other organs. Radiotherapy plays a vital role in the management of the full spectrum of small cell lung cancer, from its ability to palliate symptoms to improvements in survival [16]. Thoracic radiotherapy combined with chemotherapy improves survival in patients with limited-stage small cell lung cancer $[17,18]$. According to the National Comprehensive Cancer Network guideline, concurrent chemoradiotherapy (CCRT) is recommended for limited-stage small cell lung cancer in excess of T1-2 N0 [19]. According to reports on small cell carcinoma in other sex organs, including the uterine cervix, endometrium, and vagina, multimodality therapy is likely the treatment of choice [20]. Patients with SCOCPT never received pelvic or abdominal radiation in previous reports. It is reasonable to follow treatment trends for small cell carcinoma of the lung, since tumors are histologically indistinguishable and exhibit a similar aggressive behavior.

Second, with regard to $\mathrm{LDH}$ as a useful tumor marker of SCOCPT, CA125 (positive rate 82.4\%), NSE (85.7\%), and CA19-9 (37.5\%) have been reported as tumor markers for SCOCPT [21], but LDH has not been reported. Increased $\mathrm{LDH}$ is a prognostic tumor marker in many other solid tumors, including non-small cell lung cancer [22], breast cancer [23], and prostate cancer [24]. It has long been known that many human cancers have higher LDH levels than normal tissues [25]. The serum level of $\mathrm{LDH}$ is thought to be correlated with the tumor burden and to reflect the tumor's growth and invasive potential [26]. In this case, chemotherapy and radiotherapy transiently inhibited the growth of both tumor cells and LDH production, which led to an acute decrease in the serum $\mathrm{LDH}$ level. Because of the highly proliferative capacity of SCOCPT, serum LDH levels increased during the drug holidays. Although $\mathrm{LDH}$ has five isoforms with different distributions, it was not necessary to detect these isoforms separately because no specific isoform was characteristically increased. This is useful, because total serum LDH assessment is convenient and inexpensive [27]. Serum LDH can be a useful tumor marker to evaluate the effectiveness of the treatment and to assess the prognosis. 


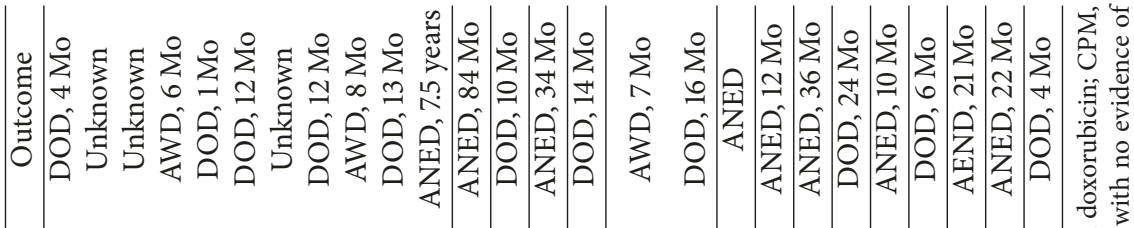

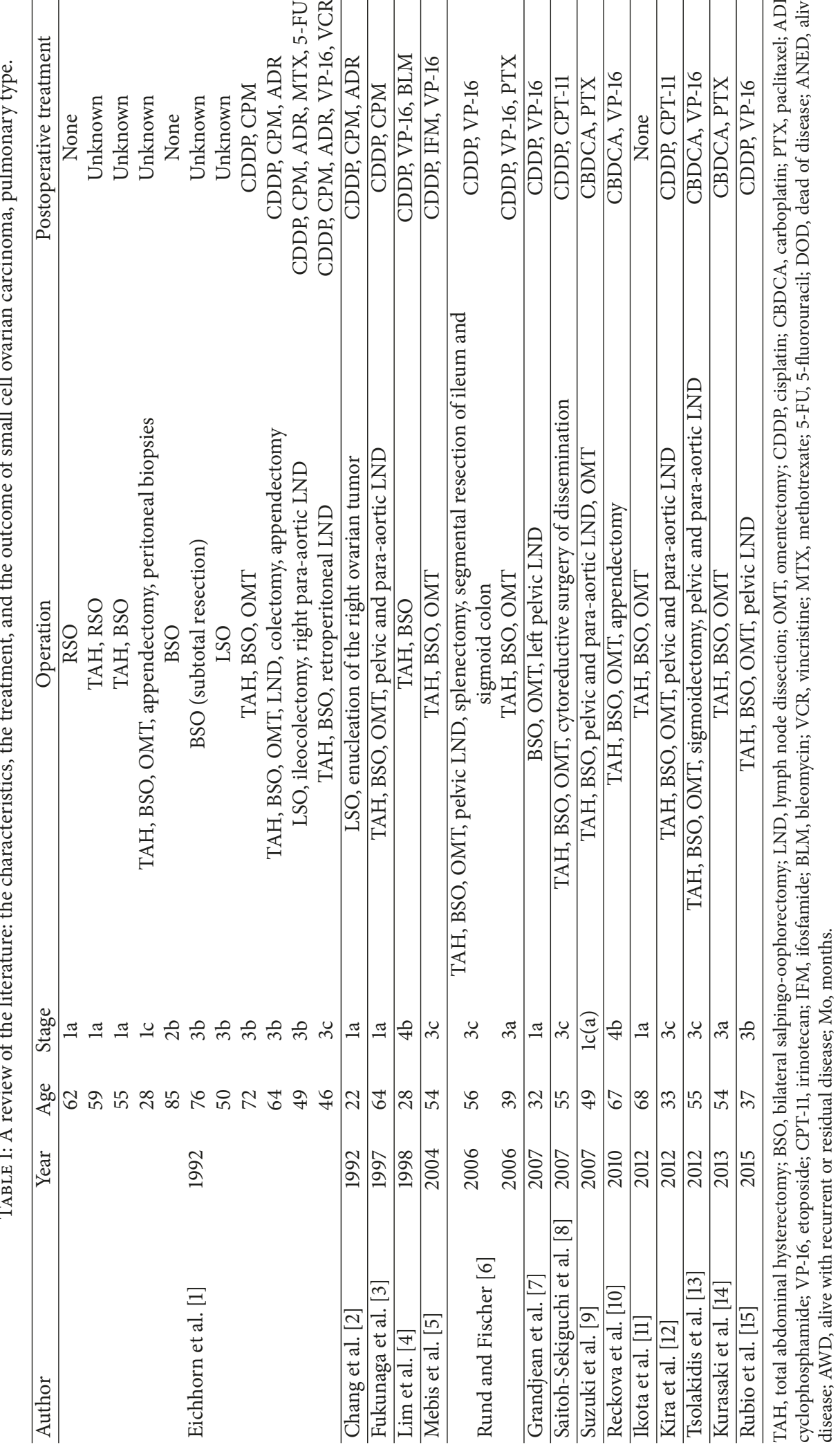




\section{Conclusion}

Palliative radiotherapy for SCOCPT can be considered in patients with abdominal swelling, and LDH might be a useful tumor marker. Radiotherapy might be considered as an option if the tumor is resistant to chemotherapy after a staging laparotomy. Furthermore, multimodality therapy might be appropriate in patients thought to be candidates for aggressive, potentially curative treatments, but further research is required to establish the treatment strategy for SCOCPT.

\section{Consent}

Written informed consent was obtained from the patient for publication of this case report.

\section{Conflicts of Interest}

The authors declare that they have no conflicts of interest.

\section{Acknowledgments}

The authors thank Dr. Yoshiro Otsuki (Department of Pathology, Seirei Hamamatsu General Hospital) and Dr. Ayse Ayhan (Department of Pathology, Seirei Mikatahara General Hospital) for their helpful comments.

\section{References}

[1] J. H. Eichhorn, R. H. Young, and R. E. Scully, "Primary ovarian small cell carcinoma of pulmonary type: A clinicopathologic, immunohistologic, and flow cytometric analysis of 11 cases," The American Journal of Surgical Pathology, vol. 16, no. 10, pp. 926938, 1992.

[2] D. H.-C. Chang, S. Hsueh, and Y.-K. Soong, "Small cell carcinoma with neurosecretory granules arising in an ovarian dermoid cyst," Gynecologic Oncology, vol. 46, no. 2, pp. 246-250, 1992.

[3] M. Fukunaga, Y. Endo, Y. Miyazawa, and S. Ushigome, "Small cell neuroendocrine carcinoma of the ovary," Virchows Archiv, vol. 430, no. 4, pp. 343-348, 1997.

[4] S.-C. Lim, S. J. Choi, and C. H. Suh, "A case of small cell carcinoma arising in a mature cystic teratoma of the ovary," Pathology International, vol. 48, no. 10, pp. 834-839, 1998.

[5] J. Mebis, H. De Raeve, M. Baekelandt, W. A. A. Tjalma, and J. B. Vermorken, "Primary ovarian small cell carcinoma of the pulmonary type: A case report and review of the literature," European Journal of Gynaecological Oncology, vol. 25, no. 2, pp. 239-241, 2004.

[6] C. R. Rund and E. G. Fischer, "Perinuclear dot-like cytokeratin 20 staining in small cell neuroendocrine carcinoma of the ovary (pulmonary-type)," Applied Immunohistochemistry \& Molecular Morphology, vol. 14, no. 2, pp. 244-248, 2006.

[7] M. Grandjean, L. Legrand, M. Waterkeyn et al., "Small cell carcinoma of pulmonary type inside a microinvasive mucinous cystadenocarcinoma of the ovary: A case report," International Journal of Gynecological Pathology, vol. 26, no. 4, pp. 426-431, 2007.
[8] M. Saitoh-Sekiguchi, K. Nakahara, T. Kojimahara et al., "Complete remission of ovarian small cell carcinoma treated with irinotecan and cisplatin: A case report," Anticancer Reseach, vol. 27, no. 4 C, pp. 2685-2687, 2007.

[9] N. Suzuki, K. Kameyama, T. Hirao, N. Susumu, M. Mukai, and D. Aoki, "A case of pulmonary type of ovarian small cell carcinoma," Journal of Obstetrics and Gynaecology Research, vol. 33, no. 2, pp. 203-206, 2007.

[10] M. Reckova, M. Mego, K. Rejlekova, Z. Sycova-Mila, Z. Obertova, and J. Mardiak, "Small-cell carcinoma of the ovary with breast metastases: A case report," Klinicka Onkologie, vol. 23, no. 1, pp. 43-45, 2010.

[11] H. Ikota, K. Kaneko, S. Takahashi et al., "Malignant transformation of ovarian mature cystic teratoma with a predominant pulmonary type small cell carcinoma component," Pathology International, vol. 62, no. 4, pp. 276-280, 2012.

[12] N. Kira, N. Takai, T. Ishii et al., "Ovarian small cell carcinoma complicated by carcinomatous meningitis," Rare Tumors, vol. 4, no. 2, p. e26, 2012.

[13] D. Tsolakidis, A. Papanikolaou, K. Ktenidis, and S. Pervana, "Primary ovarian small cell carcinoma of pulmonary type with enlarged paraaortic lymph node masses: A case report and review of the literature," European Journal of Gynaecological Oncology, vol. 33, no. 3, pp. 312-315, 2012.

[14] A. Kurasaki, N. Sakurai, Y. Yamamoto, H. Taoka, K. Takahashi, and K. Kubushiro, "Ovarian pulmonary-type small cell carcinoma: Case report and review of the literature," International Journal of Gynecological Pathology, vol. 32, no. 5, pp. 464-470, 2013.

[15] A. Rubio, M. Schuldt, C. Chamorro, V. Crespo-Lora, and F. F. Nogales, "Ovarian small cell carcinoma of pulmonary type arising in mature cystic teratomas with metastases to the contralateral ovary," International Journal of Surgical Pathology, vol. 23, no. 5, pp. 388-392, 2015.

[16] D. K. Woolf, B. J. Slotman, and C. Faivre-Finn, "The Current Role of Radiotherapy in the Treatment of Small Cell Lung Cancer," Clinical Oncology, vol. 28, no. 11, pp. 712-719, 2016.

[17] J.-P. Pignon, R. Arriagada, D. C. Ihde et al., "A meta-analysis of thoracic radiotherapy for small-cell lung cancer," The New England Journal of Medicine, vol. 327, no. 23, pp. 1618-1624, 1992.

[18] P. Warde and D. Payne, "Does thoracic irradiation improve survival and local control in limited-stage small-cell carcinoma of the lung? A meta-analysis," Journal of Clinical Oncology, vol. 10, no. 6, pp. 890-895, 1992.

[19] National Comprehensive Cancer Network. NCCN Clinical Practice Guidlines in Oncology: Small Cell Lung Cancer, In: P. Gregory, M. Kalemkerian (ed.), 2016.

[20] S. Crowder and E. Tuller, "Small Cell Carcinoma of the Female Genital Tract," Seminars in Oncology, vol. 34, no. 1, pp. 57-63, 2007.

[21] K. Münstedt, R. Estel, T. Dreyer, A. Kurata, and A. Benz, "Small cell ovarian carcinomas - Characterisation of two rare tumor entities," Geburtshilfe und Frauenheilkunde, vol. 73, no. 7, pp. 698-704, 2013.

[22] K. S. Albain, J. J. Crowley, M. LeBlanc, and R. B. Livingston, "Survival determinants in extensive-stage non-small-cell lung cancer: the southwest oncology group experience," Journal of Clinical Oncology, vol. 9, no. 9, pp. 1618-1626, 1991.

[23] J. E. Brown, R. J. Cook, A. Lipton, and R. E. Coleman, "Serum lactate dehydrogenase is prognostic for survival in patients with bone metastases from breast cancer: A retrospective analysis in 
bisphosphonate-treated patients," Clinical Cancer Research, vol. 18, no. 22, pp. 6348-6355, 2012.

[24] S. Halabi, E. J. Small, P. W. Kantoff et al., "Prognostic model for predicting survival in men with hormone-refractory metastatic prostate cancer," Journal of Clinical Oncology, vol. 21, no. 7, pp. 1232-1237, 2003.

[25] R. D. Goldman, N. O. Kaplan, and T. C. Hall, "Lactic Dehydrogenase in Human Neoplastic Tissues," Cancer Research, vol. 24, pp. 389-399, 1964.

[26] S.-Y. Suh and H.-Y. Ahn, "Lactate dehydrogenase as a prognostic factor for survival time of terminally ill cancer patients: A preliminary study," European Journal of Cancer, vol. 43, no. 6, pp. 1051-1059, 2007.

[27] R. Liu, J. Cao, X. Gao et al., "Overall survival of cancer patients with serum lactate dehydrogenase greater than 1000 IU/L," Tumor Biology, vol. 37, no. 10, pp. 14083-14088, 2016. 


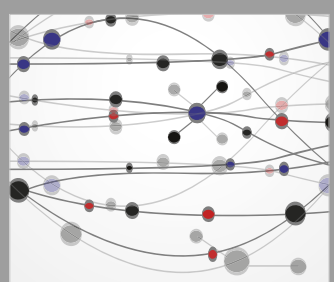

The Scientific World Journal
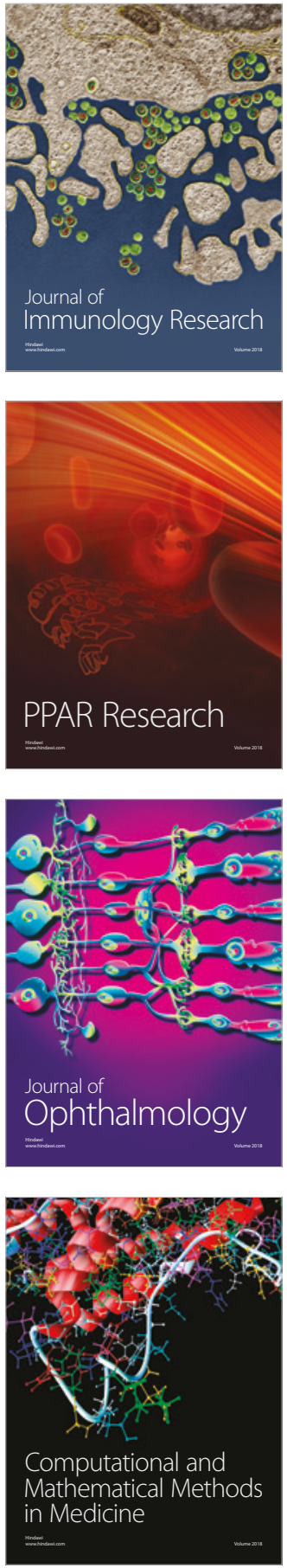

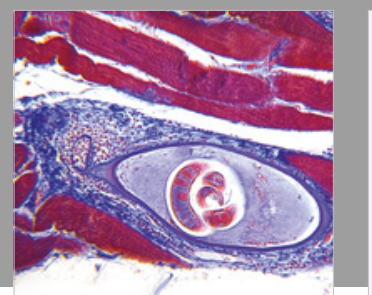

Gastroenterology Research and Practice

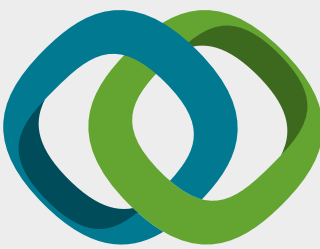

\section{Hindawi}

Submit your manuscripts at

www.hindawi.com
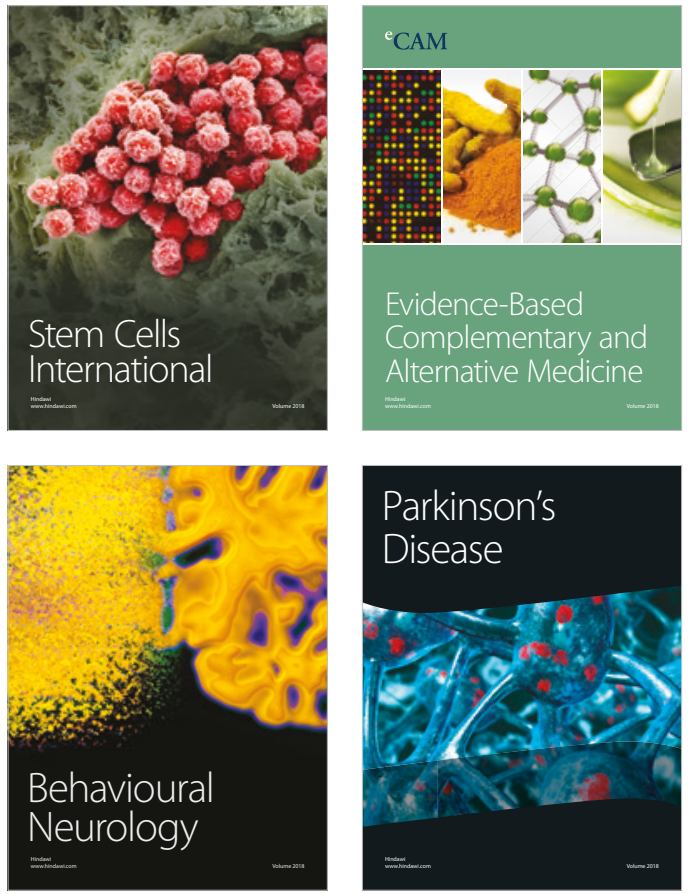

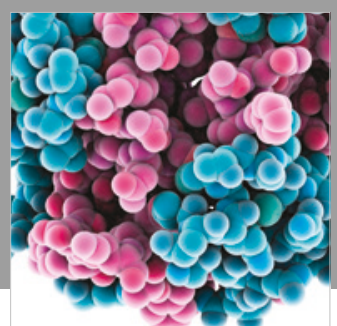

ournal of

Diabetes Research

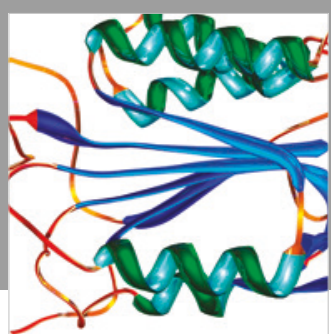

Disease Markers
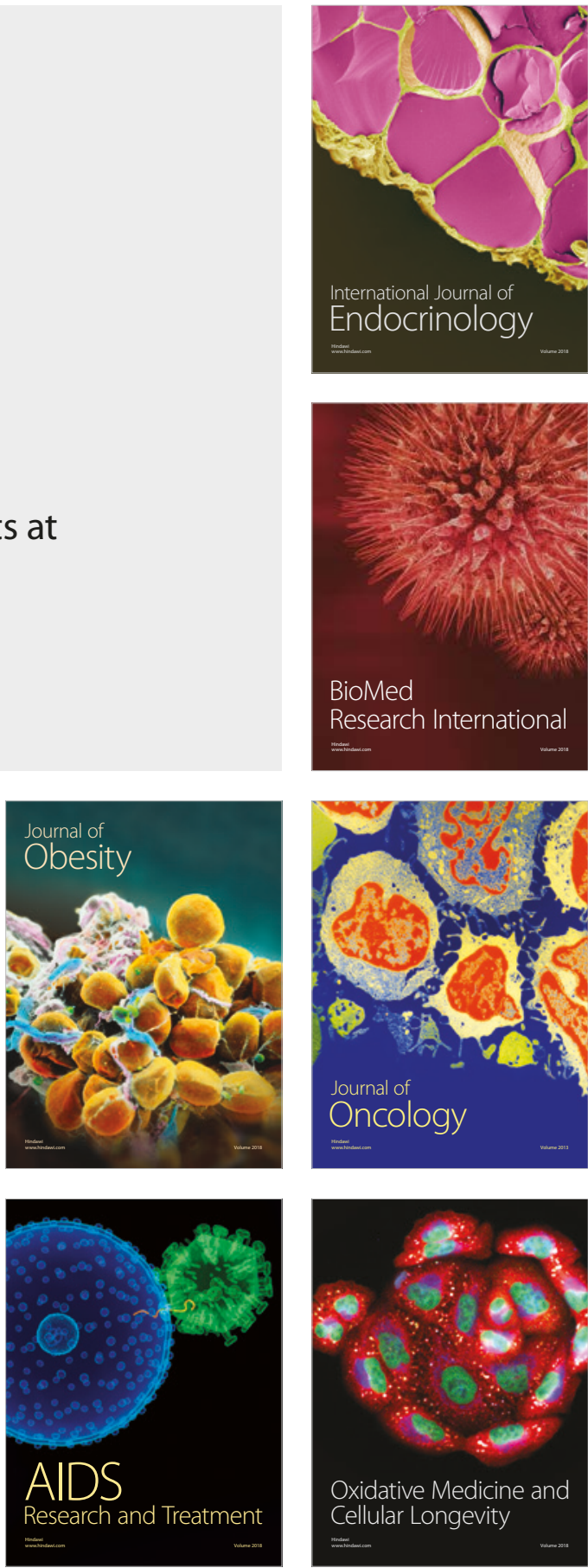